\title{
श्रीअरविन्द के चिन्तन में चेतना की परामनोवैज्ञानिक अवधारणा
}

कृष्णा चौधरी

सारांश

श्रीअरविन्द के विचार में चेतना की परामनोवैज्ञानिक अवधारणा सर्वथा नये आयामों में प्रकट हुई है। चेतना के सन्दर्भ में उनके विचार भारतीय चिन्तनधारा की ही विस्तृत अभिव्यक्ति है। उनके चिन्तन में चेतना के विभिन्न प्रचलित अर्थों को नया स्वरूप मिला और उसके सूक्ष्म से सूक्ष्मतर स्तर की अभिव्यक्ति सम्भव हो सकी है। श्रीअरविन्द ने विशेष अर्थों में चेतना को चित्-शक्ति कहा है। उनकी चेतना संबंधी अवधारणा आधुनिक युग में भारतीय मनोविज्ञान का प्रतिनिधित्व करती है और साथ ही पाश्चात्य मनोविज्ञान से उसका गहरा अन्तर भी स्पष्ट करती है। श्रीअरविन्द ने मानव जीवन में मानस चेतना का बहुत महत्त्व बतलाया है। वे मानस चेतना को विश्व चेतना से जोड़ने वाली अनिवार्य कड़ी मानते हैं। मानस चेतना को मानव जीवन के रूपान्तरण एवं उर्ध्व विकास का अनिवार्य एवं महत्त्वपूर्ण केन्द्र मानकर वे इसके सूक्ष्मतम पहलुओं को उजागर करते हैं। मानस के सूक्ष्म तलों की विवेचना ही उनके परामनोवैज्ञानिक विचारों का स्वरूप है। इस सन्दर्भ में श्रीअरविन्द मानस चेतना के अतीन्द्रिय चार लोकों की विवेचना करते हैं एवं आधुनिक मनोविज्ञान के लिए मानवीय मन के उच्च भागों में नयी संभावनाओं को तलाशने का मार्ग प्रशस्त करते हैं। मानस से अतिमानस के मध्य श्रीअरविन्द चेतना के विकास का विश्लेषण कर सर्वथा नई परामनोवैज्ञानिक अवधारणा की सृष्टि करते हैं।

कूट शब्द : चेतना, परामनोविज्ञान, मानस एवं श्रीअरविन्द।

श्रीअरविन्द के चिन्तन में चेतना के अर्थ एवं स्वरूप की नितान्त नई और मौलिक दृष्टि प्राप्त होती है। उनके विचारों में चेतना के प्रचलित अर्थों का नया रूप और सूक्ष्म से सूक्ष्मतर स्वरूप को समझा जा सकता है। सामान्यतया चेतना के अन्तर्गत वे सभी प्राणधारी आ जाते हैं, जिनमें ऊर्जा, गति, इच्छा, अनुभूति, अहं, संकल्प, विचारणाएँ, भावनाएँ इत्यादि पायी जाती हैं। चेतना के इन स्तरों में मनुष्य की चेतना प्राणिमात्र में सबसे ऊपर है। श्रीअरविन्द ने चेतना को चित्-शक्ति कहा है। उनके अनुसार चेतना केवल शक्ति ही नहीं, चेतना केवल सत्ता ही नहीं, बल्कि चेतना आनन्द भी है (Aurobindo, 1974)। मनुष्य का जीवन विश्व चेतना की एक अनिवार्य कड़ी में गुंथा हुआ है। यही कारण है कि यह जीवन के अचेतन एवं अतिचेतन स्तरों से निरन्तर प्रभावित एवं प्रेरित होते रहती है। ये प्रेरणाएँ और प्रभाव हमारे अन्दर विचारों, आदर्शों, अभीप्साओं तथा कलाकृतियों के माध्यम से अपने आपको व्यक्त करते रहते हैं और ये ही अज्ञात रूप से हमारे जीवन और भविष्य का निर्माण करते हैं। श्रीअरविन्द के शब्दों में-“"चेतना की विभिन्न श्रेणियों में सार्वभौम अवस्थाएँ पायी जाती हैं, जिनका अस्तित्व व्यक्ति के निजी दृष्टिकोण से सर्वथा स्वतंत्र है, बल्कि सच तो यह है कि मानव का व्यक्तिगत दृष्टिकोण अपने जातीय स्वभाव अथवा विकास स्तर के अनुसार चेतना की जिस श्रेणी पर निर्मित होता है,
वही उसके स्वरूप को निर्धारित करती है" (Aurobindo, 1964)।

श्रीअरविन्द के विचारों में चेतना सम्पूर्ण सत्ता की द्योतक है। उनके अनुसार मनुष्य जीवन चेतना के केन्द्र में स्थित है और इस सृष्टि के निर्माण एवं लक्ष्य की सबसे महत्वपूर्ण कड़ी है। चैतन्य सत्ता के विकासक्रम में मनुष्य ही शिखर पर आरूढ़ है और ध्येय के सर्वाधिक समीप भी है। लेकिन अभी हम मनुष्य के जिस स्वरूप को देख पाते हैं, वह उसमें अंतर्निहित अनंत सम्भावनओं का सिर्फ एक भाग है।

मनुष्य चेतना के मौलिक स्वरूप में जो ऊर्जा गतिमान है वह उसमें अन्तर्निहित सम्भावनाओं के विकास हेतु सतत प्रयत्नशील रहती है। श्रीअरविन्द के अनुसार यह आन्ततिक आन्दोलन हमेशा होता रहता है (Aurobindo, 1952)। चेतना का यह आन्तरिक प्रयास तब तक जारी रहता है जब तक कि ब्रह्माण्डीय चेतना से उसकी लय स्थापित न हो जाए। एक बार व्यष्टि चेतना का समष्टि चेतना से सम्पर्क हो जाने पर व्यष्टि चेतना का समष्टि चेतना में रूपान्तरण होना संभव हो जाता है। यह रूपान्तरण घटित होने पर मानव चेतना पिण्ड से ब्रह्माण्ड चेतना में परिवर्तित हो जाती है। इस सम्बन्ध में आचार्य पं. श्रीराम शर्मा कहते हैं कि "ब्रह्माण्डव्यापी ब्रह्म चेतना निराकार होती है" (आचार्य, 1997)। मनुष्य जीवन में ब्रह्माण्डव्यापी निराकार चेतना से सम्पर्क स्थापित करने का माध्यम मानस चेतना है। मानस 
श्रीअरविन्द के चिन्तन में चेतना की परामनोवैज्ञानिक अवधारणा 
जैसी विभूतियाँ इसी तल पर दिखायी देती है। श्रीअरविन्द कहते हैं कि यह हमारी मानसिक अवधारणात्मक क्षमता का आध्यात्मिक आधार है (Aurobindo, 1955)।

वस्तुतः हमारा सामान्य मन एक के बाद एक तथ्यों को पकड़ता है और फिर उन्हें पंक्तिबद्ध करके समझने की कोशिश करता है, जिसे हम आत्मविश्लेषण की प्रक्रिया कहते हैं। यही उसके कार्य करने का तरीका भी है और प्रकृति भी। परन्तु उर्ध्वमानस में चेतना को तथ्यों को समझने या जानने के लिए आत्मविश्लेषण जैसा कार्य सम्पादित नहीं करना पड़ता और न ही अवयवों को जोड़ने-तोड़ने की आवश्यकता पड़ती है। श्रीअरविन्द के अनुसार यहाँ मानस चेतना निम्न स्तरों (मन) की तरह अनगिनत चीजों पर उतना निर्भर नहीं करती, क्योंकि उर्ध्वमानस में तथ्यों का सारद्रव्य स्वाभाविक पकड़ में आने लगता है। वे अलंकारिक भाषा में इसे अन्तर्जान की एक नन्हीं बूँद कहते हैं। आधुनिक मनोविज्ञान की दृष्टि से यह एक स्वस्थ और विचारशील मस्तिष्क की तरह है, जहाँ भान्तियाँ कम पनपती हैं और अनेक क्षमतायें प्रतिभाओं के रूप में अभिव्यक्त होने लगती हैं। यहाँ मन की अतीन्द्रिय क्षमता का पहला परिचय प्राप्त होता है। परन्तु श्रीअरविन्द मानस चेतना के इस स्तर को मनोवैज्ञानिक नहीं, अपितु आध्यात्मिक दृष्टि से अतिमानस की ओर पहला कदम मानते हैं।

\section{उद्भासित मानस}

श्रीअरविन्द के अनुसार इस स्तर पर मानस चेतना अपनी विचारशीलता पर निर्भर नहीं रह जाती, अब वह स्व-प्रकाशित प्रकाशमय दृष्टि का उपयोग करने लगती है। वे कहते हैं कि विचार के माध्यम से जो सत्य प्राप्त होता है, वह वस्तुतः सत्य नहीं, सत्य की 'प्रतिनिधि-प्रतिमा' मात्र है (Aurobindo, 1955)। उद्भासित मानस में विचारने की आवश्यकता नहीं रह जाती, क्योंकि इसके पूर्व अन्तर्ज्ञान की जो नन्हीं-नन्हीं बूँदें चेतना को सत्य की झलक अथवा विचारों को प्रकाशित कर रही थी, अब यहाँ वह बूँद न होकर एक धारा में बदल जाती है। इस धारा में विषय स्वतः प्रकाशित हो उठता है। मानस चेतना के अन्तर्जगत का सबसे महत्त्वपूर्ण पक्ष जो यहाँ प्रकट होता है, वह है-चेतना में सौन्दर्योपासक विशेष भाव। इसे श्रीअरविन्द ने मानस चेतना का 'सर्वप्रथम मूलभूत परिवर्तन' कहा है (Aurobindo, 1951)।

यह मानस चेतना की उत्साहपूर्ण, प्रेम और आनन्दमय अवस्था है। यहाँ पर अर्थात् मानस के इस नवीन चेतना स्तर में सृजनात्मक शक्तियाँ स्वतः खिल पड़ती है, विशेष रूप से काव्य क्षेत्र में। श्रीअरविन्द का मत है कि चेतना के
उर्ध्वलोकों का स्वरूप व्यक्त करने के लिए कविता सबसे अच्छा साधन है (सत्प्रेम, 1999)। चेतना के उर्ध्वमानस स्तर में सृजनात्मकता और सौन्दर्य का समूचा विस्तार प्रकट होता है। काव्य और कलायें इसी को अभिव्यक्त करती है।

परन्तु श्रीअरविन्द के विचारों में यहाँ इस तथ्य को भी समझ लेना अत्यन्त आवश्यक है कि मानस चेतना जैसे-जैसे उर्ध्वलोकों में यात्रा करती है, उन अलग-अलग लोकों अथवा स्तरों पर उसकी कुछ कमियाँ भी होती हैं। ये कमियाँ चेतना के उस स्तर पर पहुँचकर ही प्रकट होती हैं। श्रीअरविन्द उद्भासित मानस की कमियों का उल्लेख करते हुए कहते हैं कि इस स्तर पर प्रायः सूक्ष्म दृष्टि खुल जाती है और चेतना में रूपकों, अभिव्यंजनाओं की बाढ़ सी आ जाती है। इसमें कभी-कभी क्रमविहीन और प्रकाशयुक्त ऐसे तीव्र स्पन्दन होते हैं, जिन्हें चेतना संभाल नहीं पाती है। यदि इसके उत्साह और उत्तेजना को नीरवता से न बाँधा गया, तो पूर्णतः प्रकाशित मानस क्षेत्र पर कब्जा कर उसे नाटकीय रूप से तोड़-मोड़ कर विकृत बना देती है (सत्प्रेम, 1999)। सम्भवतः योग एवं मनोविज्ञान में कई बार साधना क्षेत्र में विक्षिप्त हो जाने का कारण यही होता है तथा गंभीर मनोरोगों की सृष्टि भी चेतना के इसी स्तर पर त्रुटियों के कारण होती है।

वस्तुतः श्रीअरविन्द के अनुसार उद्भासित मानस का मूल द्रव्य पारदर्शी नहीं, केवल पारभासी होता है। उच्च प्रकाश का आभास पाने के कारण ही इसका स्वरूप अथवा सार आनन्द है। किन्तु इससे ऊपर आगे बढ़ने के पूर्व अधिक पवित्र बनने एवं भीतर नीरवता, शांति और समता को बढ़ाने की खास आवश्यकता होती है।

अन्तर्बोधि मानस - श्रीअरविन्द के अनुसार मानस चेतना के इस स्तर में ऐसी चेतन प्रकाशमय क्षमता है, जो उर्ध्व एवं उद्भासित मानस की तुलना में कहीं अधिक ज्ञान के निकट है। यह चेतना की अन्तर्दृष्टि का स्तर है। जब स्व की चेतन शक्ति चेतना के प्रकाश के साथ ऐसा समझने लगे कि उसे अपने विषय का स्पष्ट ज्ञानात्मक बोध हो रहा है, तो इसी दृष्टि को अन्तर्दृष्टि कहते हैं (Aurobindo, 1955)। श्रीअरविन्द का कहना है कि प्रकाशमय ज्ञान का प्रारम्भ अन्तर्दृष्टि के ही स्तर से होता है, क्योंकि इसी स्तर में उच्चतर क्षेत्र का संज्ञान स्पष्ट रूप में प्रारम्भ होता है। यहाँ हमारे मानस की नीरवता में से ज्ञान बिजली की तरह फूटता है।

श्रीअरविन्द ने अन्तर्बोधि मानस को 'परम सत्य की एक स्मृति' कहा है (Aurobindo, 1955)। यह मानस के दोनों गोलार्द्धों- निम्न एवं उच्चगोलार्द्ध का मिलन बिन्दु है। एक, मानस का वह भाग है, जो अन्धकारमय लोकों से यात्रा 
करके वहाँ पहुँचता है और दूसरा, जो परम ज्ञान ज्योति से प्रकाशित उच्च लोक में निवास करता है। यह मिलन उद्भासित के आनन्द से भिन्न विशेष प्रकार के आनन्द से चेतना को भर देता है। योग में इसे समाधि अवस्था का प्रथम द्वार कहा गया है। श्रीअरविन्द अपनी अनुभूतियों में कहते हैं कि इसकी व्याख्या करना असम्भव है। इस नवीन दृष्टि की व्याख्या करते ही तीन-चौथाई भाग लुप्त हो जाता है और हम इस रूपान्तरकारी शक्ति को कुछ और ही अभिव्यक्त कर देते हैं। योग साधना में अन्तर्दृष्टि को साधक की प्रथम सफलता माना जाता है, क्योंकि यहीं से यथार्थ ज्ञानमय यात्रा में चेतना प्रवेश करती है तथा इसके बिना उच्च लोकों में प्रवेश असम्भव है।

\section{अधिमानस}

अधिमानस मानस तथा अतिमानस के बीच की सर्वप्रमुख कड़ी है (Aurobindo, 1955)। यहाँ चेतना की ज्ञानमय दृष्टि सार्वभौम रूप से देखने में समर्थ हो जाती है। यह मानस में विश्वव्यापी चेतना का प्रकटीकरण है। इसे श्रीअरविन्द ने मानव की चेतना के लिए अति दुर्लभ कहा है। उनके अनुसार चेतना का यह लोक देवताओं का लोक है। महान धर्मप्रवर्तकों का प्रेरणा स्रोत है। सारे धर्मों ने यहीं जन्म लिया है। उच्च कलायें यहीं जन्म लेती हैं। यह मानस चेतना का ही एक स्तर है, उच्चतर शिखर है।

श्रीअरविन्द के अनुसार अधिमानस में चेतना 'स्थिर प्रकाश-सिन्धु' के समान हो जाती है। अब तक के देश-काल के पर्दे यहाँ हट जाते हैं। यहाँ आलोक का अविराम प्रवाह, सतत् सार्वभौम दृष्टि, विश्व आनन्द, विश्वव्यापी सौन्दर्य, सार्वभौम प्रेम जैसे चेतना का परिचय बन जाता है। कहा गया है कि वैदिक ऋषियों में यही सम्पूर्ण चेतना प्रतिष्ठित थी। श्रीअरविन्द अधिमानस चेतना की विशेषता बताते हुए कहते हैं कि मानस चेतना के इस स्तर तक सभी भागों से प्रवेश किया जा सकता है। जैसे-प्रगाढ़ धर्मनिष्ठा, प्रखर काव्य प्रेम, चिन्तन, कला, वीरता के उत्कर्ष अर्थात् मनुष्य को अपने वर्तमान मानस की सीमाओं का अतिक्रमण करने के लिए जिस-जिस वस्तु से सहायता मिले, उन सब के द्वारा वह वहाँ पहुँच सकता है। मानस के इन चार स्तरों के बाद चेतना अतिमानस के क्षेत्र में प्रवेश करती है। अतिमानस उनकी परामनोविज्ञान अवधारणा का आदर्श भी है। श्रीअरविन्द अतिमानस को 'चरम सत्य चेतना' कहते हैं 
चौधरी

संभावनाओं को जन्म देती है। इसके साथ ही मनोविज्ञान जगत् को अतिचेतन क्षेत्र में प्रवेश करने के लिए सर्वथा नूतन दृष्टि भी प्रदान करती है। श्रीअरविन्द के परामनोवैज्ञानिक विचारों का महत्त्व यह है कि आज आधुनिक परामनोविज्ञान जहॉ मन की अतीन्द्रिय सामर्थ्य को मानस चेतना की विशेष योग्यता अथवा प्रतिभा के रूप में प्रस्तुत करता है, वहीं श्रीअरविन्द के विचारों में मानस चेतना इस जीवन के समग्र 